\title{
XAS and TEM Study of the TiN Thin Films Grown by the pulsed DC sputtering Technique assisted by balanced magnetron.
}

\author{
A. Duarte-Moller ${ }^{1,2}$, H. Esparza-Ponce ${ }^{2}$ and C. González-Valenzuela ${ }^{3}$ \\ ${ }^{1}$ Departamento de Física, Universidad de Sonora, Blvd... Rosales s/n \\ Hermosillo, Son., 83000, México \\ ${ }^{2}$ Centro de Investigación en Materiales Avanzados, S. C. \\ Miguel de Cervantes 120, Complejo Industrial Chihuahua, \\ Chihuahua, Chih. 31109, México \\ ${ }^{3}$ Siemens de México, Subdirección Chihuahua, Chihuahua, Chih. México
}

Hard coatings and their applications continuously are in progress. The thin films of transition metal nitrides have a broad range of potential applications that goes from microelectronics to the metal-mechanics industry or in biological implants. The research of TiN is still on in actuality for the different science branches like the above mentioned [1]. In this work a serie of different $\mathrm{TiN}_{\mathrm{x}}$ thin films were grown by the DC-sputtering technique. The purpose was to study through XAS and TEM interpretation, how the different amounts of $\mathrm{N}_{2}$ during growing thin TiN thin films affects the stoichiometry of the TiN deposited.. Also the results obtained determinate how to interpret the spectra to see the different valences of Ti in TiN, are working. The results were supported with the EXAFS, XANES and TEM analysis. This work concludes the adequated conditions for this experiment to obtain TiN as thin film by the DC sputtering assited by balanced magnetron at room temperature and aconcludes which XAS spectra are the finger print for valences of Ti.

XAS experiments were carried out in the SSRL (Stanford Synchrotron Radiation Laboratory) beam line 7-3 assisted by a Lytle detector by meassuring the fluorescence emission. A singular problem apperas when the resonance of the Si diffraction lines are overlapped into the XAS spectra, however tbese diffraction peaks are easily removed by deglitching the spectra in the Win XAS software. Typical runs were about 1 hour collecting absorption data aroun de $\mathrm{Ti}-\mathrm{L}_{23}$ edge located at an energy of $4.5 \mathrm{KeV}$. TEM analysis were done in a Philips CM200 HR-TEM.

Fig. 1 shows the XANES spectra of samples and are compared with the respective TiO2 standard. As we can see there is a difference among them in the pre-edge where the valence state is present. In this figure the valence is shown by arrows. Fig. 2 displays the RDF of the films and that corresponding to the grown at the $\mathrm{P}_{\mathrm{N}}=25 \mathrm{mtorr}$, the lattice parameter measured is $0.439 \mathrm{~nm}$. This value is in very good agreement with those results already published for TiN [2].

Finally in Fig. 3 appears the TEM inage of the sample grown at $\mathrm{P}_{\mathrm{N}}=25 \mathrm{mTorr}$. This figure shows the Si substrate, the interface and the TiN film. Is evident the good quality of the film. 
The conditions at room temperature with the DC- sputtering technique to obtain the stoichimetry TiN were established and also for sub-stoichiometry. The lattice a obtained for the TiN thin film, is in total agreement with JCPDS 38-1420.

The authors give special thanks to Daniel Lardisaval, Armando Reyes y Arturo Hernández for them excellent technical support and assistance.

\section{References}

[1] Y.G. Shen, Y.W. Mai, W.E. McBride, Q.C. Zhang and D.R. McKenzie, Thin Solid Films 372 (2000) 257.

\section{[2] JCPDS-INTERNL. CENTRE FOR DIFFRACTION DATA LICENSE 38-1420}
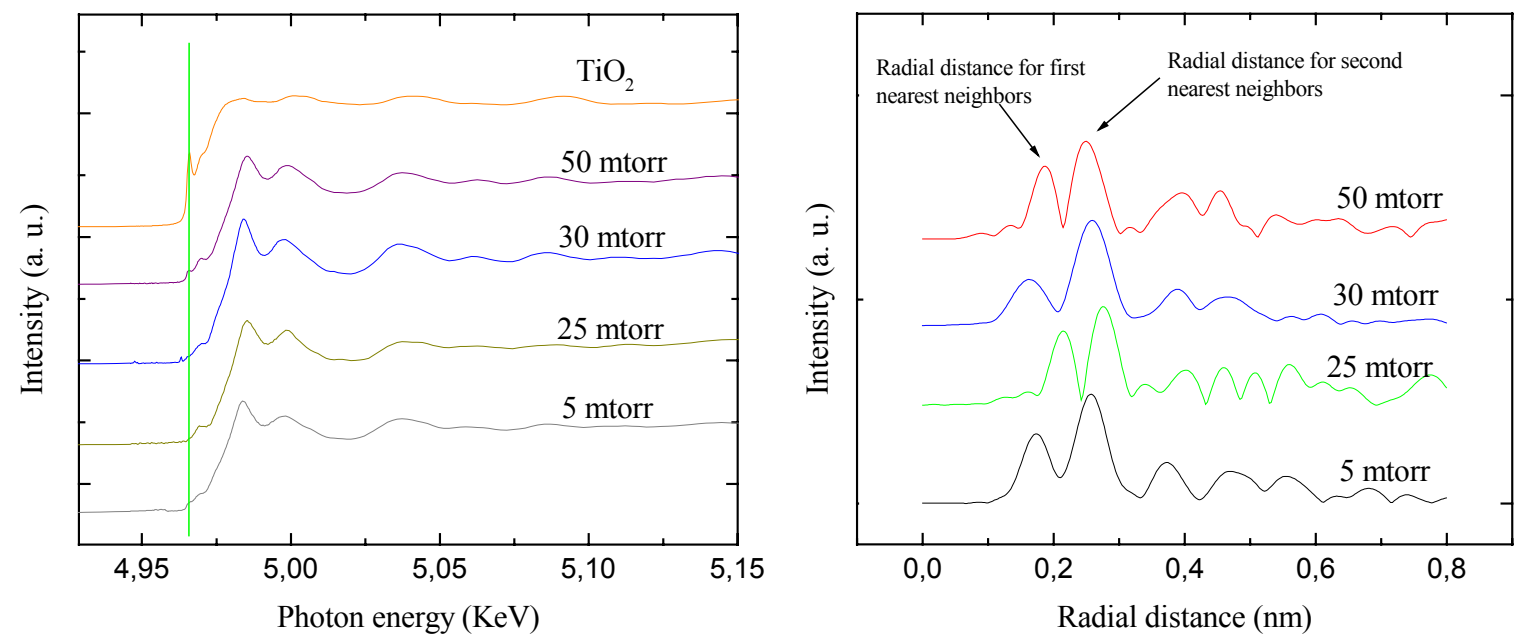

Fig. 1. XANES spectra of TixNy thin films

Fig. 2. RDF spectra showing the atomic position

Fig. 3. TEM image of the

TixNy; $\mathrm{x}=1=\mathrm{y}$

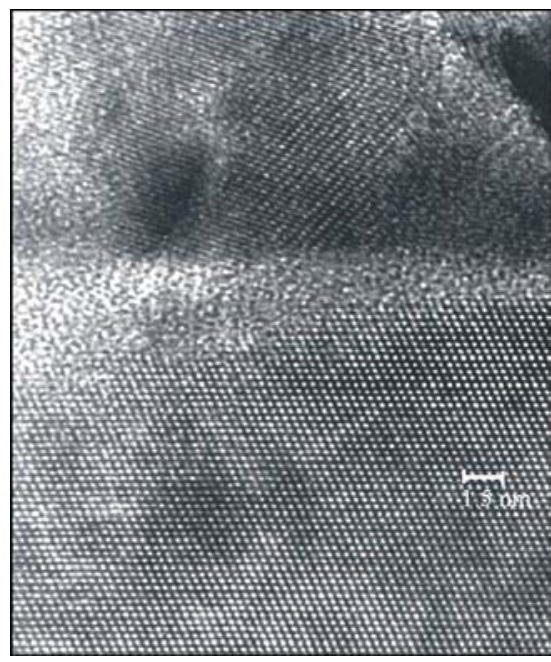

TiN thin film

Interface

Si (111) substrate 